\title{
PERSONAL CHARACTERISTICS OF SLOVENIAN MANAGERS IN BUSINESS NEGOTIATIONS
}

\author{
Bruno ZAVRŠNIK ${ }^{1}$, Vojko POTOČAN ${ }^{2}$ \\ ${ }^{1}$ University of Maribor, Faculty of Economics and Business, 2000 Maribor, Razlagova 14, Republic of Slovenia. E- \\ mail: bruno.zavrsnik@uni-mb.si \\ ${ }^{2}$ University of Maribor, Faculty of Economics and Business , 2000 Maribor, Razlagova 14, Republic of Slovenia.
}

Accepted 10 November, 2013

\begin{abstract}
Negotiations are an integral part of our life, both personal as well as at business level. The negotiations are old just as much as the human race and covering all human activities. They are the most complex forms of relationships between people, which represent a number of interdisciplinary knowledge and skills. The secret of successful negotiations is usually good preparation of negotiators. Negotiations do not begin when we meet with opposite negotiator, but much earlier. Today, due to lack of time is often decided that negotiators are poorly prepared to negotiate. These negotiators are calculating that their unwillingness can be replaced during the negotiations, but experts believe that this is the biggest mistake made by the negotiators. Negotiations are also an integral part of the tasks performed by managers in companies responsible for selling products and services. The purpose of this study was to find out negotiations in practice, who are negotiators, how Slovenian managers prepare themselves for negotiations, how to negotiate, what negotiating tactics are used, what personal qualities are emphasized in negotiations and, finally how to evaluate themselves as negotiators.
\end{abstract}

Keywords: Business negotiations, negotiation process, negotiation tactics, negotiators characteristics, Slovenian negotiators

\section{INTRODUCTION}

Negotiation is a dialogue between two or more people or parties, intended to reach an understanding, resolve point of difference, or gain advantage in outcome of dialogue, to produce an agreement upon courses of action, to bargain for individual or collective advantage to craft outcomes to satisfy various interests of two people/parties involved in negotiation process. Negotiation is a process where each party involved in negotiating tries to gain an advantage for themselves by the end of the process. Negotiation is intended to aim at compromise (Ury, 1998).

In private life we are not even aware of the constant negotiating roles. However, when negotiations are an integral part of our business functions, we are more systematic, we more precisely follow our objective achieved through negotiation by using various negotiation tactics and strategies.
The negotiator can be everyone. Every individual has specific negotiating skills, which can be improved by constant upgrading and with further education and training (Katz et al., 2008).

As people go through everyday life, they encounter various situations which they consciously recognize as negotiable. Yet even with this conscious recognition, some of those people negotiate while others do not.

\section{BUSINESS NEGOTIATIONS}

Traditionally, negotiations were often expected to end up with one party winning and the other one losing. This is referred to as a zero-sum game based on a win-lose, all-or nothing proposition. In some labour-management disputes the results could even end up in a lose-lose situation, especially when either or both parties adopt extreme positions that lead up to a "take-it-orleave-it" impasse and end up in costly, lengthy, and mutually dissatisfying settlements. The new approach makes a win-win outcome possible, 
especially when parties use a common set of principles and a common framework for effective negotiations.

Fisher and Ury (1983), foremost proponents of the principled negotiations strategy (or negotiation on the merits), propose four basic guidelines to be observed in the process:

1. Personalities must be separate from the problem.

2. Interests must be the focus, not positions.

3. Options and alternatives must be considered before decisions are made.

4. Criteria and other objective standards must be the basis for evaluating claims.

On the first guideline, the human factor must be considered - that negotiators are human beings with emotions, values, beliefs and different backgrounds and viewpoints. Being human, all negotiators are unpredictable. If both parties sincerely desire to arrive at a workable agreement, they must be sensitive and respectful to each other's person. The point is not to defeat the other side as an enemy, or score points against him as in a debate. The main aim should always be up front, which is - to solve the problem or resolve the issue between them and thereby arrive at an agreement that is mutually satisfying and acceptable. The negotiations should end up without anyone "losing face", feeling bitter and humiliated, or being personally aggrieved. If not, the process can develop into a personal confrontation, with each side forgetting the real issues and the main objective. The interpersonal relations between the parties will tend to become entangled with their discussions of the substantive points in the bargaining and the issue of personalities may come into play. Therefore, it is well to "separate the people from the problem (Gatchalian, 1998).

The negotiations are necessary; there must be at least a partial difference in the interests of both parties. Negotiations are useful for solving conflicts. This means that the two parties for a commodity that you want both sides, but it is not available in sufficient quantity for both. If there is no conflict negotiations are not necessary. (Kavčič, 1996).

Negotiators communicate with each other, exchange the necessary information and move from phase to phase. The stage is completed when you make it possible to pass to the next stage or if you agree that negotiations have no more sense and you terminate negotiations.
First, negotiators are trying to understand the needs of the other side and get as much information as it comes to negotiations and finally, when negotiators agree on certain items, they sign an agreement (Fleming, 1998; Usunier, 2000).

Each negotiator decides to negotiate in order to meet their own interests and reach the goals (Donohue, 2004). Before negotiators decide to negotiate, they should think carefully whether the circumstances to negotiate are good enough, because negotiation requires resources, time and engagement (Završnik, 2007).

\section{EMPIRICAL FINDINGS}

\section{Characteristics of the sample}

The main research instrument for empirical investigation was questionnaire. The questionnaire was sent via email to the 265 sales managers from different Slovenian companies and from different business activities. We sent 68 questionnaires to large companies, 83 to medium-sized and 114 to small companies. During a four week period a total of 76 surveys was returned. The response rate was $28.68 \%$. We have received complete questionnaire from $32.35 \%$ of large companies, $40.96 \%$ of medium-sized companies and only $19.30 \%$ of small companies. From the total of 76 questionnaires completed by 58 men and only 18 by women, which means in \% that $76.32 \%$ of the respondents were male and women only $23.68 \%$.

\section{The survey results}

Many definitions say that a good negotiator always prepare for negotiations, which must be planned in advance, defined and have refined content.

Planned negotiations weaken the impact of unpredictable factors, assists in decision making, points out the bottlenecks to allow coordinated work, encourages creative atmosphere, give a solution to plan in advance.

The result of the analysis shows (Figure 1) that only half $(53.95 \%)$ of respondents are always prepared to negotiate. It is often prepared by $35.53 \%$ respondents, $10.53 \%$ occasionally and never none, which certainly shows awareness of the importance of preparations for the negotiations. For successful negotiations are also important activities implemented by the participants (Table $1)$. 


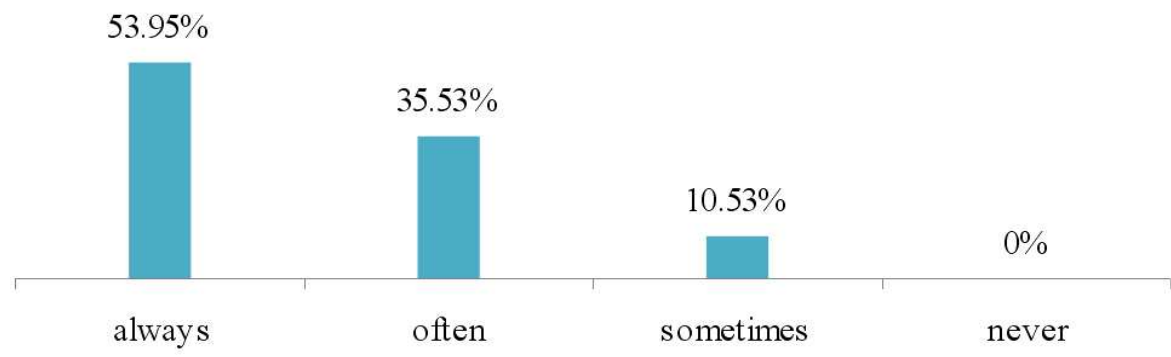

Figure 1: The frequency of the preparations for the negotiations

Table 1: Activities to prepare for negotiations

\begin{tabular}{|l|c|}
\hline \multicolumn{1}{|c|}{ Activities } & Answers in \% \\
\hline Identification of the main goals & 16.62 \\
\hline Consultation with colleagues & 15.09 \\
\hline Collection of information on topic negotiations & 12.79 \\
\hline Collection of information on negotiating partner & 11.51 \\
\hline Collection of information about past negotiations with this partner & 10.23 \\
\hline Determining negotiation strategies and tactics & 7.67 \\
\hline Determine the minimum goals & 6.91 \\
\hline Determine the alternative goals & 6.65 \\
\hline Determining the place of negotiations & 5.37 \\
\hline Determining the time of negotiations & 4.86 \\
\hline Determine the negotiating team and negotiators competence & 2.30 \\
\hline
\end{tabular}

Identification of the main goals is with $16.62 \%$ the most common activity to prepare for negotiations, with $15.9 \%$ followed by consultation with colleagues.

The result shows that the consultation with colleagues and different information for the negotiators mean strong support in determining the main negotiating goals.

Each negotiator has good and bad characteristics, which affects the result of negotiations. Respondents ranked characteristics from 1 to 7 , where 1 means the most important characteristic of a good negotiator and 7 the least important characteristics of a good negotiator.

For the most important characteristic of good negotiators, respondents determined honesty, reliability and determination (Table 2). As the least good characteristic was defined flexibility.

Likewise, respondents evaluated the bad characteristics of negotiators (Table 3).

For the most important characteristic of bad negotiators respondents determined lying, arrogance and misleading. As the least bad characteristic was defined inflexibility.
Table 2: Good negotiators characteristics

\begin{tabular}{|l|c|}
\hline Good characteristics & Rank \\
\hline Fairness & 1 \\
\hline Reliability & 2 \\
\hline Decisiveness & 3 \\
\hline Persuasiveness & 4 \\
\hline Patience & 5 \\
\hline Honesty & 6 \\
\hline Flexibility & 7 \\
\hline
\end{tabular}

Table 3: Bad negotiators characteristics

\begin{tabular}{|l|c|}
\hline \multicolumn{1}{|c|}{ Bad characteristics } & Rank \\
\hline Lying & 1 \\
\hline Arrogance & 2 \\
\hline Misleading & 3 \\
\hline Looking for strife & 4 \\
\hline Dishonest & 5 \\
\hline Indecision & 6 \\
\hline Inflexibility & 7 \\
\hline
\end{tabular}

Negotiators in the negotiations process use different tactics. There are the tools to implement negotiation strategies for achieving the negotiating goals. Almost half of the respondents (47.37\%), chos as the most commonly used tactics "slicing" which means slice a larger deal up into a number of smaller complete deals and then to achieve a favourable outcome for each individual component (Table 4). 
Table 4: The most commonly used negotiation

\begin{tabular}{|l|c|}
\hline \multicolumn{2}{|c|}{ tactics } \\
\hline SACTICS & Answers in\% \\
\hline Good Guy/Bad Guy & 47.37 \\
\hline $\begin{array}{l}\text { Setting the extreme } \\
\text { requirements }\end{array}$ & 21.05 \\
\hline No authority & 11.84 \\
\hline Take it or leave it & 6.53 \\
\hline Just one more thing & 2.63 \\
\hline Blinding maneuver & 0.00 \\
\hline Other tactics & 0.00 \\
\hline
\end{tabular}

In the second place is tactics "good and bad guy". One person acts in an aggressive and pushy way, making unreasonable demands and requiring compliance. The other person then acts in a kindly and friendly way, asking nicely - and getting compliance.

The good guy (or gal, of course) may apologize for the bad guy, or plead for compliance because the bad guy is being horrible to the good guy too.

In the third place is "setting the extreme requirements", the fourth "no authority", followed by tactics "take it or leave it »and "just one more thing".

\section{CONCLUSIONS}

Negotiations are one of the most common and the most important activities of every individual and are an essential part of decision-making in personal and business life (Reardon, 2005). Their point is balancing of interests, different needs, desires and expectations of individuals to help achieve the goals that lead to an agreement with the opposite side.

Negotiations must take place within a collaborative environment for both sides that can be successful.
Trust and cooperation (two basic negotiation values) must be the guiding principle in the negotiations, which is necessary to point out the ability of persuasion and the possibility of a conscious influence on change of attitudes and behaviour, which is reflected in the success of the negotiations.

Negotiations are also an integral part of the work carried out by the managers - in the companies responsible for selling products and services. There is an old rule which says that in business you do not get what you deserve but what you gain by negotiation. This indicates the importance of business negotiations.

\section{REFERENCES}

Donohue, W. (2004). Critical moments as 'flow' in negotiation. Negotiation Journal, 20(2), 147-151.

Fisher, R., \& Ury, W. (1983). Getting to Yes: Negotiating Agreement without Giving in. New York: Penguin Books.

Fleming, P. (1998). Successful Negotiating In a Week. London: Hodder and Stoughton.

Gatchalian, J. C. (1998). Principled negotiations - a key to successful collective bargaining. Management Decision, 36(4), 222-225.

Katz, N. H., \& Pattarini.N.M. (2008). Interest-based negotiation. Journal of Communication Management, 12(1), 88-97.

Kavčič, B. (1996). Spretnost pogajanja. Kranj: Moderna organizacija.

Reardon, K. (2005). Becoming a Skilled Negotiator. Hoboken, NJ: John Wiley \& Sons.

Ury, W. (1998). Od nasprotovanja do sodelovanja. Ljubljana: Gospodarski vestnik.

Usunier, J. C. (2000). Marketing Across Cultures. New York: Prentice Hall.

Završnik, B. (2007). Poslovna pogajanja v medkulturnem okolju. Maribor: Ekonomskoposlovna fakulteta. 